Djalma Thürler*

Universidade Federal da Bahia

Duda Woyda**

Universidade Federal da Bahia

\title{
A Língua Política e a Política Poética na Poesia Encarnada de Alex Simões
}

Resumo: Num diálogo interdisciplinar, nosso objetivo é observar como a obra poética de Alex Simões participa na redefinição de uma poesia que gostaria de ser política. Uma "política da poesia" toma então forma, nas pegadas de Jacques Rancière e da sua "política de estética", que coloca a perspectiva política como uma crítica do presente e um desejo de transformação, de uma relação para o real, uma produção de sentido e uma concepção do espectador que é a sua. A partir de referências fronteiriças-queer, os autores reconhecem uma política da poesia em sua dimensão estÉtica, em processos híbridos entre política da diferença e estética, que servem como novas políticas de subjetivação.

Palavras-chave: Interdisciplinaridade, poesia brasileira, Alex Simões

Abstract: In an interdisciplinary dialogue, our goal is to observe how the poetic work of Alex Simões contributes to the redefinition of a type of poetry that aims at being political. A "politics of poetry" then takes shape in the footsteps of Jacques Rancière and his "politics of aesthetics", taking political perspective as a critique of the present and a desire for transformation, from a relation to the real, a production of meaning and its own conception of the spectator. Based on queer-frontier references, the authors recognize a politics of poetry in its aesthetic dimension, in hybrid processes between politics of difference and aesthetics, which serve as new policies of subjectivation.

Keywords: Interdisciplinarity, Brazilian poetry, Alex Simões 
Toda poesía es un palimpsesto en el que se superponen y se confunden naturaleza e historia. José Juan Saer

O presente trabalho constitui etapa de um projeto formal de pesquisa cuja hipótese indica que alguns discursos artísticos contemporâneos brasileiros e ibero americanos, incluindo Portugal e Espanha, nos últimos trinta anos são orientados para a construção de um sistema político-estético que, por meio de variadas linguagens e diversos discursos (Colling 2017; Santos 2020) relacionam este processo artístico à transformação histórica, política e cultural de uma sociedade ligada aos acontecimentos de ordem hegemônica e dominação política. Segundo Valmir Santos,

constam das décadas de 1990 e de 2000 avanços consideráveis (ante o deserto de iniciativas) em termos de políticas culturais públicas conquistadas, em grande parte, por meio das mobilizações de artistas e produtores, muitos deles estudantes ou professores universitários - a expansão do acesso ao ensino superior e a implantação de políticas de cotas raciais a pessoas pretas, pardas e indígenas se fizeram notar. (Santos 2020: s.p)

Se alguns artistas, apesar da sua "instável consensualidade" (Raposo 2015), são considerados artivistas (Colling 2019a; Trói 2018), acreditamos que outros se encontram numa encruzilhada de maior sofisticação entre a arte e as ideias políticas, como é o caso da poesia de Alex Simões (1973), poeta baiano, que codifica uma determinada ideologia política em suas formas poéticas, desde a reivindicação da forma poética tradicional e sua retradicionalização regida por princípios de métrica e consonância como condição fundamental para a expressividade poética, até o formato de publicação dos poemas.

No ensaio "Sobre la poesía” (1988), Juan José Saer afirma que a poesia é uma síntese entre a natureza e a história, como revela a epígrafe que abre este artigo (Saer 2014: 220). Para Sérgio Carvalho, professor da Escola de Comunicação e Artes, da USP, "poesia é a tentativa desesperada de dar sentido ao que não faz sentido” (Carvalho 2020: s.p.). Entre uma e outra impressão, notamos que na poesia de Alex Simões, há uma relação permanente de troca entre o seu texto e o contexto que o emergencia, por isso seus poemas não apenas comentam o mundo exterior, mas também dependem dele, das influências do ambiente sócio-histórico e cultural que os preexiste e que, evidente, poderia explicar certas orientações de conteúdo e de sentido.

Seus versos, assim, configuram uma representação de que estar no mundo é também uma questão fundamental de defender pontos de vista. Por isso, cada palavra corresponde a um gesto que toma o seu lugar e significado numa luta coletiva, o que concorda com as palavras de Gérard Genette, quando este diz que "un texte s'inscrit dans l'histoire de ceux qui l'ont promu" (Genette 1972: 18). Para Alex Simões, a poesia é então: 
um lugar indiscutivelmente de exercício radical da liberdade através da linguagem verbal. $\mathrm{E}$ um lugar também importante de expressão de sentimentos, de afetos, de reflexões sobre a própria linguagem, questões que afetam as pessoas. É uma linguagem transdisciplinar por excelência. Ficou muito patente uma relação da poesia com a poesia escrita no papel, mas ela tem uma origem, e a poesia que me interessa não esquece essa origem que está relacionada à música, ao canto, à dança, a um lugar sagrado, no sentido em que um ateu pensa e é fascinado por esse sagrado. (Simões 2018a: para. 3)

As observações de Georges Pompidou, em Préface de l'anthologie de la poésie française, poderão ser úteis para esta questão:

Qu'est-ce donc que la poésie ? Bien savant qui le dira. Qu'est-ce que l'âme ? On peut - nous l'avons tous fait au collège - analyser un poème, étudier composition, vocabulaire, rythme, rime, harmonie. Tout cela est à la poésie ce qu'un cœur qui bat est à l'âme. Une manifestation extérieure, non une explication, encore moins une définition. Si donc je voulais m'approcher d'avantage d'une définition de la poésie, je la chercherais plutôt dans ses effets. Lorsqu'un poème, ou simplement un vers provoque chez le lecteur une sorte de choc, le tire hors de lui-même, le jetant dans le rêve, ou au contraire le contraint à descendre en lui plus profondément jusqu'à le confronter avec l'être et le destin, à ces signes se reconnait la réussite poétique. ${ }^{2}$ (Pompidou 1961: 9)

Queremos dizer com o exposto que o que soa como atraente na dicção poética de Simões é seu desempenho duplo, seja a busca pelo rigor da forma, que o faz teimar e limar e sofrer e suar, seja a potência das impressões e imagens transmitidas pela descoberta de seu poema, situando, assim, o fundamento da sua poesia tanto no que é visível, mas ainda, no que é invisível, mais esquivo na pessoa.

Para abordar esta questão, para a qual as palavras de Georges Pompidou servem de álibi, mas que requer outras ferramentas interdisciplinares de análise, vamos nos basear em poemas de Alex Simões, alguns deles, extraídos do blog que o autor mantém atualizado (https://toobitornottoobit.blogspot.com), outros do livro trans formas são [sic], ${ }^{3}$ de 2018, em diálogo com referências fronteiriças-queer, que reconhecem modos de subjetivação para as artes, pensados a partir da política da poesia. Isto significa pensar na poesia contemporânea em sua dimensão estÉtica, ${ }^{4}$ aliada a processos híbridos entre política da diferença (Miskolci 2012; Colling 2019) e estética (Rancière 2009; 2012), que servem como antídoto contra os aprisionamentos e modelizações da arte burguesa, bem como a invenção de possíveis (Rolnik 2008) a partir de outras políticas de subjetivação (Rolnik 2008; Thürler 2019).

trans formas são abre a coleção "contemporaneidades periféricas” da Editora Organismo e, segundo informações de lançamento, busca visibilizar produções de sujeitos historicamente subalternizados e as diversas formas de inscrição do contemporâneo. ${ }^{5}$ 
Como observa Aleixo, na orelha do livro, trata-se de

um livro sobre e sob aquele tanto de vida que ainda respira, dentro da gente \& da coisa-mundo, quando já quase tudo presenta-se como destroço, ruína, vertiginosa beira, vórtice, naufrágio e o que sei eu. 0 desafio, para o sujeito poeta que escreve este livro, parece ser o de mover-se em meio ao que quer que signifique alguma possibilidade de aproximação destes dois sintagmas cujas existências, hoje, correm risco igual de apagamento pela necropolítica: sujeito e poeta. (Aleixo 2018b: orelha)

O livro é dividido em três partes: trans formas são (19 poemas), poemot!com (8 poemas) e bordado caótico (11 poemas), "que perguntam à poesia, às palavras, às pessoas, aos animais, às coisas e ao próprio poeta o que virão/viremos a ser. A obra também fala sobre distintas temporalidades convivendo, nem sempre pacificamente, com o aqui e o agora" (Correio Nagô 2018: para. 3) - "que porra é mesmo o contemporâneo" (Simões 2018b: 19). Para tanto, Simões recorre a procedimentos estéticos, principalmente, a intertextualidade, para deixar em suspenso o assombro de estar vivo, apesar da necropolítica (Mbembe 2018) contra a qual se insurge pela poesia. "É o que bate na memória de uma pele - neste caso, preta, gay, cis, entre outras circunstâncias - e que assombra pela beleza, pelo horror, pelo afeto, pelo susto mesmo", revela Alex Simões (apud Correio Nagô 2018: para. 1).

É o que o poeta revela em Autopsicografia ll ou Poesia Chã, que, ao parafrasear o título do importante poema de Fernando Pessoa, caminha de "mãos dadas" mesmo é com Carlos Drummond de Andrade e sua poesia do tempo presente que canta "para os vivos por motivos óbvios" (Simões 2018b: 17). Seus versos, ressalta, "falam do mundo e para

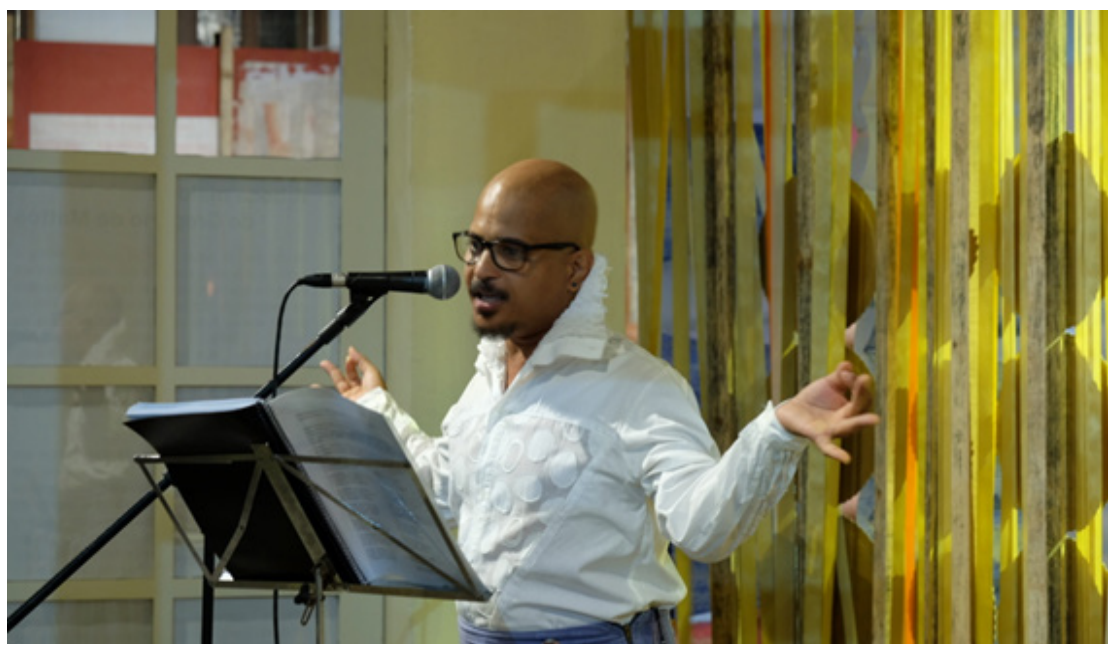

Alex Simões em foto de Edgar Oliva 
o mundo este/porque daquele já se falou muito" (ibidem). Este mundo, para Simões, é o que impõe uma experiência limite ao corpo preto, o não humano, o sub-humano, o anônimo, o de nome genérico. Por isso quer o poeta "poder cantar impunemente/sem ter de agradecer por estar vivo" (idem: 16).

Ainda investigando Drummond, Simões, no poema "45", de 2018, demonstra que sua dicção poética é fundamentalmente diálogo:

no meio do meio de que caminho

não sei. só sei que me desencaminho

cada vez mais e melhor. entre perdido

e bem desencontrado descarto mapas

em meio aos achados e perdidos

dos quês e quens do tempo que visitam

- ora suaves, ora turbulentos -

a cabeça e o coração oca e cheio

respectivamente independente-

mente do caos sangrento lá fora

aqui me encontro aqui me desencontro

aqui e só aqui eu sei que existo.

eu sei? que sei eu? agora não é

tarde nem cedo: é tudo o que tenho ${ }^{6}$

Vestígio da consciência aguda da inadequação, "o mundo este" é, antes de mais nada, o local do racismo estrutural, da violência física e simbólica, da negação da identidade e da negação histórica, mas, também, um lugar de ressonância que dispõe o público a ouvir seu àgò ${ }^{7}$ e o reconhecer o poeta como ator na história, afinal, como revela em $\mathrm{Meu}$ Canto pras Paredes, de 2014:

o preconceito é uma parede enorme

contra a qual desde sempre me empurraram

mas se tentaram e não me executaram

é que aprendi bem cedo que não dorme

o apontado: preto bicha pobre

no paredão cresceu e ficou forte

ainda com a dor que o véu da morte

bem do seu lado alguns amigos cobre

e é por eles que não me vitimo

nem quero mais derrubar a parede

apenas canto para além de um íntimo 
desejo: reforçar rizoma e rede cheia de nós, que não estou só, sou vivo. picho a parede: verso afirmativo ${ }^{8}$

Neste ensaio, queremos tentar construir a ideia de que a poesia de Simões é uma poesia encarnada, uma poesia de "afirmação da vida" (Simões 2018a), aquela que faz transparecer quem somos e o que desejamos, poética que tem vida, existência, que não é um texto neutro. Poesia encarnada, reconhecida pela voz e pela técnica como importante tática de definição e construção do sujeito e da coletividade, do rizoma e da rede, é poesia que está na encruzilhada da interlocução, do reconhecimento de si próprio e do outro como sujeitos. Não à toa, chama atenção a harmonia marcante entre aspectos formais e de conteúdo em seus poemas.

Sobre a forma, o poeta afirma que esta foi legitimada pela Faculdade de Letras, da Universidade Federal da Bahia, sua grande escola e de onde extraiu suas bases acadêmica e erudita. Como explica em entrevista a Fabrício Brandão,

Vou dar um exemplo concreto e relativamente recente. Participei de um processo de seleção, no qual mandei um projeto de poemas, e tirei uma nota muito baixa na minha avaliação pessoal. Foi algo abaixo da média. Foi um poema que escrevi muito puto, chamado "Balada de um poeta ruim para si mesmo", e ali tem muito de uma frustração, uma chateação, irritação, mas é usando terça rima, fazendo referências a Dante, pensando num mote em que eu desenvolvo, e vou falando nisso ao longo do poema, e que está em "O Demônio da Teoria”, de Antoine Compagnon. (Brandão 2016: para. 10)

Ainda na mesma entrevista, o poeta revela duas tendências de sua poesia cabralina - forma e conteúdo -, assumindo "a posição do engenheiro, que (...) suprime brechas de linguagem por ondem pudessem se insinuar imprecisões, sombras ou mistérios" (Barbieri 1997: 143). Como diz Simões:

Eu parto fundamentalmente da forma, e é meio complicado dizer isso, mas parto dela. Esteticamente, penso em termos de poesia. Em projetos estéticos em geral, penso a partir de formas. Escrevo coisas muito diferentes de sonetos. Versos livres, haicais, baladas, enfim. Mas eu geralmente penso na forma que vou usar. Essa adequação entre forma e conteúdo é mais do que uma adequação. Existe uma organicidade que foi conquistada. E fico muito lisonjeado quando isso é reconhecido porque, às vezes, quando falam de mim, ressaltam muito essa condição de ser expertise, de ser um bom formalista, mas na verdade não é o que me interessa. É importante, sim, o domínio da linguagem, mas me interessa mesmo é dizer coisas. (Brandão 2016: para. 8) 
Essa busca pela forma/fôrma pode ser notada em uma postagem sobre o Soneto Edipiano, ironicamente intitulada "fôrmas do soneto: estudos para fôrmas, soneto edipiano", no blog ${ }^{9}$ que o autor mantém atualizado na internet.
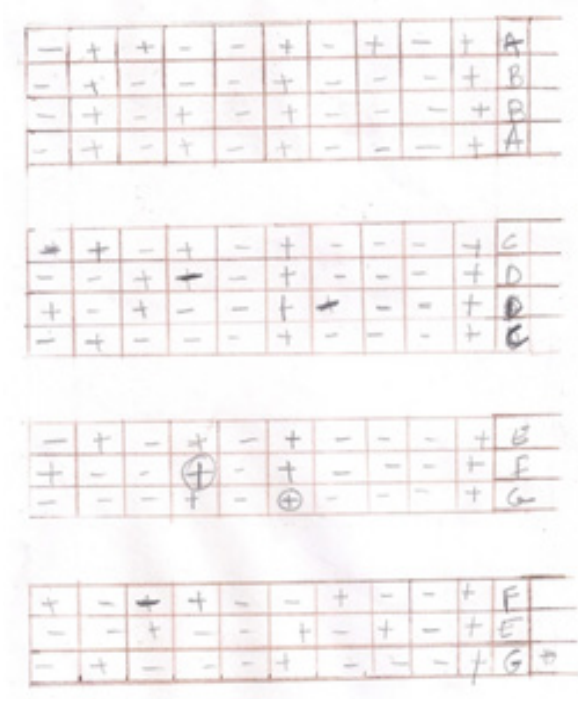

Print extraído do blog do autor

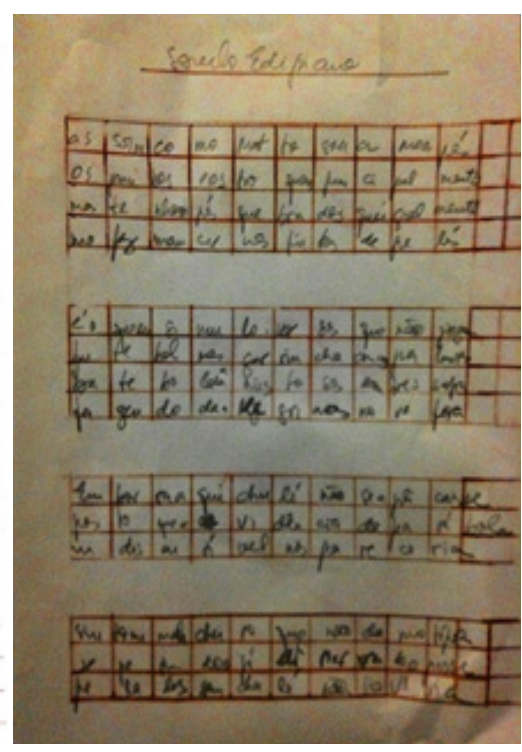
.

.

Por outro lado, os poemas de Alex Simões confirmam as impressões de Tatiana Nascimento de que

\begin{abstract}
há um giro paradigmático irreversível em curso na literatura de autoria negra/lgbtqi+, um giro de proporções cosmológicas; y ainda que de raiz revanchista, de frutos emancipatórios. Frente às expectativas/estereótipos coloniais de que o teor dessas obras se ativesse, formalmente, com relação ao seu sistema expressivo e de conteúdo, a um caráter denuncista/reativo, a produção que avalancha a década de 10 do século XXI se apresenta cada vez mais anuncista/ criativa, montando, desde as autoras varias que a tem escrito, lugares possíveis frente ao impossível colonial, seu silenciamento racista heterocisnormativo, sua limitação poética. (Nascimento 2020: 12; grifo nosso)
\end{abstract}

Em resposta à violência do impossível colonial, ou nas palavras de Luiz Antônio Simas e Luiz Rufino, do "carrego colonial” (Simas/Rufino 2019: 6), a resistência tomou ao longo da história várias formas, seja através de ações macropolíticas e sindicais, seja através das artes, incluindo a literatura, e lutou durante várias décadas para reconstruir uma identidade negra, participar da escrita da história e estabelecer os fundamentos de um Estado democrático. Nos anos 70, a poesia foi particularmente ativa como uma 
força de resistência e luta, criando e depois animando uma vontade coletiva de destruir as estruturas de opressão e, por essa razão, "teve um impacto significativo no ambiente de medo e no vazio cultural, promovidos pela censura e pela violência da repressão militar que dominava o país naquela época", como nota Heloisa Buarque de Hollanda, "conseguindo reunir em torno da poesia um grande público jovem, até então ligado mais à música, ao cinema, aos shows e aos cartoons" (Hollanda 2019: 149).

No caso de Alex Simões, trata-se, portanto, de considerar sua poesia não apenas como um produto (de uma época, de uma sociedade, de uma luta), mas também como um processo, como uma dinâmica, cujo lançamento nos anos 70 anunciava uma evolução a longo prazo, em vez da efêmera existência que muitos críticos queriam imaginar, céticos da relevância de uma literatura que procurava participar da luta política da população marginal, parafraseando Heloísa Buarque de Hollanda, marginal da vida política do país, marginal do mercado editorial, e, sobretudo, marginal do cânone literário.

De fato, atualmente, a questão da relevância tem sido frequentemente colocada a partir de uma perspectiva político-identitária e não artístico-literária, refletindo a dificuldade de pensar a poesia marginal além de seu contexto específico de produção; assim, temas importantes da pauta social contemporânea, como representação e a representatividade se tornam armadilhas estéticas e os discursos dos poetas, baseados nesses dois eixos, têm sido capazes de levantar questões cruciais da relação entre poética e política, já trabaIhada substantivamente por Jacques Rancière, a quem chamamos em auxílio. Particularmente nos interessa destacar a ideia de política que ronda toda a sua obra pensada como "atividade que reconfigura os âmbitos sensíveis nos quais se definem objetos comuns. Ela rompe a evidência sensível da ordem 'natural' que destina os indivíduo e os grupos ao comando ou à obediência, à vida pública ou à vida privada, votando-os sobretudo a certo tipo de espaço ou tempo, a certa maneira de ser, ver e dizer" (Rancière 2012: 59-60). Tanto Rancière como Rita Segato pensam que a natureza é uma invenção (Segato 2018), ou seja, que a realidade é sempre objeto de uma ficção, ou, nas palavras de Rancière,

de uma construção do espaço no qual se entrelaçam o visível, o dizível e o factível. É a ficção dominante, a ficção consensual, que nega seu caráter de ficção fazendo-se passar por realidade e traçando uma linha de divisão simples entre o domínio desse real e o das representações e aparências, opiniões e utopias. A ficção artística e a ação política sulcam, fraturam e multiplicam esse real de um modo polêmico. $O$ trabalho da política que inventa sujeitos novos e introduz objetos novos e outra percepção dos dados comuns é também um trabalho ficcional. Por isso, a relação entre arte e política não é uma passagem da ficção para a realidade, mas uma relação entre duas maneiras de produzir ficções. (Rancière 2012: 74-5)

Desse modo, a política, teria o papel importante de corromper as evidências naturais; afinal, "só existe política quando essas maquinarias são interrompidas pelo efeito de uma pressuposição que lhes é totalmente estranha", como explica Rancière em outro 
texto, "e sem a qual no entanto, em última instância, nenhuma delas poderia funcionar: a pressuposição da igualdade de qualquer pessoa com qualquer pessoa, ou seja, em definitivo, a paradoxal efetividade da pura contingência de toda ordem" (Rancière 1996a: 31).

A lógica da política, então, seria o avesso do avesso da lógica da polícia, esse "conjunto dos processos pelos quais se operam a agregação e o consentimento das coletividades, a organização dos pobres e a gestão das populações, a distribuição dos lugares e das funções dos sistemas de legitimação dessa distribuição" (idem: 41). Ou seja, é a polícia e não a política a responsável pela manutenção da ideia de natureza e, consequentemente, pela viabilização do modo de vida burguês, do "inconsciente colonial-capitalístico" (Rolnik 2018: 36); em outras palavras, é a polícia quem controla os modos econômicos de produções subjetivas, a permeabilidade de corpos e desejos (Thürler 2011: 248). Assim, muitas vezes a polícia tem equivocadamente se confundido à política, seja pela obtenção de um consenso, seja pelo estabelecimento da ordem. Rancière, no entanto, continua a falar de política dando-lhe outro significado, mais adequado, como uma noção relevante quando se refere à dialética conflituosa entre a política (por oposição ao poder) e a polícia. A política, por esse prisma, existe para "perturbar a ordem da polícia, (...) uma modificação singular do que é visível, dizível, contável (...). Antes de ser um conflito de classes ou de partidos, a política é um conflito sobre a configuração do mundo sensível na qual podem aparecer atores e objetos desses conflitos (...)" (Rancière 1996b: 374). Ou ainda:

Le politique est la rencontre de deux processus hétérogènes. Le premier est celui du gouvernement. Il consiste à organiser le rassemblement des hommes en communauté et leur consentement et repose sur la distribution hiérarchique des places et des fonctions. Je donnerai à ce processus le nom de police. Le second est celui de l'égalité. Il consiste dans le jeu des pratiques guidées par la présupposition de l'égalité de n'importe qui avec n'importe quoi et par le souci de la vérifier. Le nom le plus propre à désigner ce jeu est celui d'émancipation. ${ }^{10}$ (Rancière 2004: 112)

Por não entender estética como uma teoria da arte, Rancière distingue entre "estética primária" e "práticas artísticas". A primeira seria uma repetição da estética transcendental de Kant aplicada à política, ou seja, o estudo dos princípios da sensibilidade $a$ priori, tendo o espaço e o tempo como formas puras de intuição sensível. Espaço e tempo não são conceitos empíricos nem realidades em si, mas sim intuições a priori da nossa sensibilidade que decidem o que podemos experimentar e a extensão dos nossos conhecimentos. A política, para Rancière, é ela própria estética num sentido transcendental, determina a partilha do sensível, delineia a fronteira entre o visível e o invisível, e dá a todos um lugar na sociedade. A política é estética "num sentido kantiano - eventualmente revisitado por Foucault - como o sistema das formas a priori determinando o que se dá a sentir. É um recorte dos tempos e dos espaços, do visível e do invisível, da palavra 
e do ruído, que define tanto o lugar e o que está em jogo na política como forma de experiência" (Rancière 2009: 16). Por tudo isto, seguimos mais de perto Jacques Rancière que, longe de ambientes consensuais, renova o pensamento da política como dissenso, já que o consenso, por definição, é contrário à vida política.

Aliás, uma primeira ideia sobre os regimes da arte pensados por Rancière (2012) é que estes são diferentes modos de ser da arte que correspondem a diferentes modos políticos de sensibilidade ou, como diz o autor, são referência altamente estimulante do ponto de vista filosófico e político a diferentes modos de partilha do sensível, uma vez que a arte é produzida e desenvolvida num quadro político social e cultural. É nesse sentido que, para Rancière (2009), a arte é sempre política porque o que é arte em cada época depende de um regime de inteligibilidade, visibilidade ou identificação - um regime que é essencialmente político e que determina uma comunidade de significados:

De hecho, la generación de dicho espacio, la redistribución de objetos y sujetos, lugares e identidades, espacios y tiempos, visibilidades y significados, eso sería precisamente la política. No el ejercicio del poder y la lucha por el mismo, sino, ante todo, la conformación de un espacio específico, la delimitación de una esfera particular de la experiencia, de objetos planteados como comunes y que responden a una decisión común, de sujetos capaces de designar a esos objetos y de argumentar sobre ellos. La política es el conflicto mismo sobre la existencia de este espacio, sobre la designación de objetos que comparten algo común y de sujetos con una capacidad de lenguaje común. (Vilar 2017: 266)

Denilson Lopes ${ }^{11}$ colabora com essa discussão em um relato em sua rede social, Facebook, quando escreve sobre uma palestra que dera no exterior:

Não vou falar de negros, índios, Bolsonaro, Mariele, nem da floresta Amazônica que se incendeia uma vez mais nem do coronavirus (sic) que já nos fez vice-campeões mundiais de mortos. Sinto um mal-estar sem palavras vindo do pequeno público. Começo a falar de Modernismo, dos anos 30, no Rio de Janeiro, vanguardistas sim, mas homens, brancos, conservadores, católicos. Alguns levantam e continuo na minha crença que os livros podem dizer o que as pessoas não sabem e que a políticas dos autores não são as mesmas que a políticas das obras. Mas parece que aqui e lá os leitores querem saber das boas intenções, dos bons sentimentos traduzidos em palavras como empatia, acolhimento, lugar de fala. De repente uma raiva me vem. Não quero ser recebido como representante do meu país. A eles a estética a nós o documento social. Eles definem sobre o que devemos escrever e a nós só escutam quando é um eco narcísico e vitimista. Espelho, espelho meu quem sobre (sic) mais do que eu? Sigo na palestra sem supresa (sic) no tempo definido. Afinal fui convidado. Até se surpreendem pela qualidade dos trechos que mostro. Estou sendo cruel, injusto talvez com alguns. Só queria esquecer agora este país e este momento e mergulhar no último dia da vida de Virgílio no romance de Herman Broche, na última carta de Camilo Castelo Branco, no último sonho que 
Verlaine teve de Rimbaud. Não sei como terminei a palestra. Lembro de perguntas gentis. Um café. Depois desapareci na luz da cidade. Sabendo que aquele não era mais o meu lugar. (Lopes 2020: s.p.)

O que se quer dizer é que temos pensado numa espécie de ativismo artístico que tem se esmerado em trabalhar constantemente na desconstrução das estruturas de opressão geradas pelo cistema (Vergueiro 2015: 15) colonial-capitalístico (Rolnik 2018: 104) aumentando a conscientização de uma comunidade em cujo nome e por quem falam. Em um país onde a raça, a sexualidade, o gênero e o status social - "o apontado: preto bicha pobre" - têm sido objeto de uma luta política feroz, a questão da língua, de escrever poesia enquanto "prática micropolítica reativa" (Preciado 2018: 16) nos parece decisiva. O reconhecimento de uma humanidade triplamente marginalizada (preto, pobre e bicha) pelo mundo branco, que se engajara precisamente numa desumanização sistemática e institucionalizada, exigia como pré-requisito o reconhecimento interseccional de sua própria humanidade, uma tarefa particularmente pesada desde que as noções de povos superiores e inferiores haviam sido internalizadas ao longo dos anos graças a uma organização colonial implacável.

Portanto, nessa relação que ilustra a denúncia de Denilson Lopes está explícita "a crise da arte ou sua captação fatal pelo discurso" (Rancière 2009: 11), que na arte é dimensionada pela "imediatez ética". Em seu discurso e reivindicações sociais, a poesia é então marcada por uma afirmação, uma dimensão total e não negociável do compromisso do sujeito com a transformação imediata do mundo, com o giro decolonial (Quijano 2007), que pode ser melhor visualizada pela oposição "imediatez ética"/“eficácia estética”. Assim, esse modelo de arte dimensionado pela "imediatez ética" age de forma direta, antimetafórica, "de resistência óbvia” (Nascimento 2019: 18), artivista, e pretende uma ação que objetiva mudanças sociais e políticas "causando a generalização do espetáculo ou a morte da imagem" (Rancière 2009: 11-12). Como diz Tatiana Nascimento, "temos nos acostumado com o dever da denúncia (que rende inteligibilidade imediata, legitimidade, reconhecimento) e por vezes nos esquecemos do direito - humano ao devaneio - vocação da arte" (Nascimento 2019: 18).

Quando relacionamos o Modelo Pedagógico da Imediatez Ética ao artivismo, estamos concordando com Alexandre Gomes Vilas Boas para quem "a arte engajada ou ativista se torna política a despeito de seus atributos estéticos e escolhas técnicas" (Boas 2015: 48). Para Carlos Henrique de Lucas, Carlana Faria Rocha e Anselmo Peres Alós,

arte em forma de protesto, ato e performance acontecem não como uma pausa ou momento artístico no meio do protesto ou dos palcos, é o próprio protesto realizado através da arte de modo a provocar embates, questionamentos e reivindicações.

As pessoas envolvidas com artivismos denunciam injustiças sociais com intuito de transformar, chamar a atenção para violências, criar empatia entre o público e as causas sociais. (Lucas et al. 2020: 67; grifo nosso) 
Marcelo De Trói, em sua dissertação de mestrado, elabora um esquema que tenta fazer entender essa discussão. Para o autor, as produções artivistas ${ }^{12}$ possuem diferentes intensidades e podem estar divididas em dois polos, mais próximas ou mais distantes de uma certa radicalidade estética: "o polo do mercado, do capital, institucional, paranoico, molar, territorializante e o polo queer, anárquico, subjetivo, esquizofrênico, molecular, desterritorializante" (Trói 2018: 94):

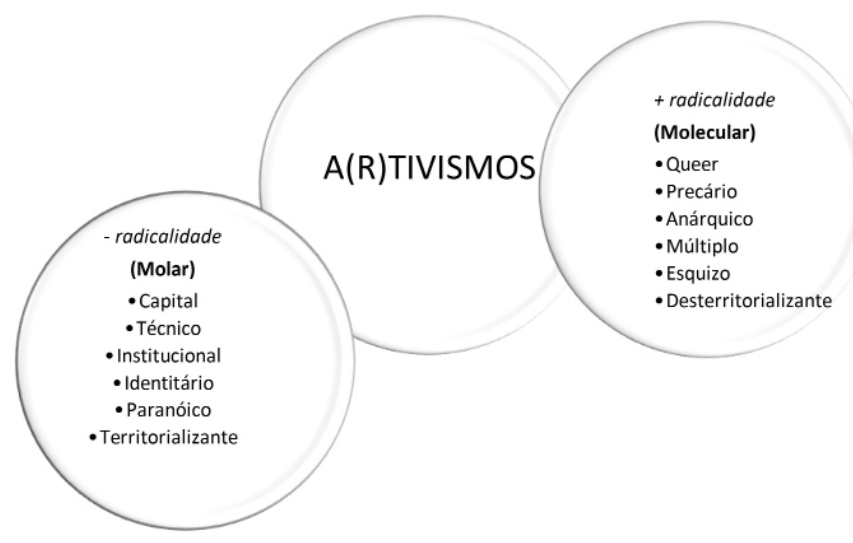

Gráfico retirado de Trói (2018), adaptado pelos autores.

Segundo Trói, "quanto mais próximo do polo molecular, mais radicais serão as produções. Se mais próximas do molar, estarão mais afinadas com o estabilishment, com as ideias de representação e as benesses do mercado" (idem: 94). Mas, continua o autor, "mesmo no jogo de intensidades, de locais de fala, territorialização e desterritorialização, os a(r)tivismos trazem em si uma ideia de desnaturalização e desconstrução, fundamentos herdados a partir do impacto dos estudos queer no campo social e, sendo assim, no campo subjetivo" (ibidem).

Embora não concordemos totalmente com as categorias eleitas por Trói (Não haveria alguma produção em arte que fosse, ao mesmo tempo técnica e anárquica?), achamos que a visualidade do esquema pode colaborar com nosso argumento central, o de que, retomando Tatiana Nascimento, em detrimento da construção estética, que seria, em si, uma construção política, a literatura dimensionada pela "imediatez ética" tem se transformado em um "estereótipo da resistência constante que nos congela no frame da denúncia" (Nascimento 2019: 23).

A poesia de Simões, no entanto, é caracterizada por vozes que negociam esses dois aspectos (ético/estético), criando uma outra relação de agenciamento, sem deixar de colocar no centro da sua poética a questão da representação da sua experiência; pelo 
contrário, entende que falar de/em si mesmo é um compromisso, ainda mais num país onde a opressão é tão generalizada, que nada - quer atue ou a sua ausência - escapa ao domínio da política. Simões reconhece que "a história tem mostrado que, em períodos de crises, a poesia, os poetas, as poetas passam a ter alguma relevância social" (Simões 2018a: para. 15). Como explica o poeta,

Isso está relacionado, e, claro, acho que isso também é resultado de investimento de políticas públicas de valorização de sujeitos e subjetividades que foram marginalizadas, pessoas negras, mulheres, LGBTs, e todos os lugares de marginalização, deficientes físicos, ciganos, etc. Em algumas partes, segmentos desses contingentes foram encontrando a arte e especialmente a poesia como lugar de expressão. (ibidem)

Porém, Simões expressa sua poesia em sua estreita relação com a oralidade e a escrita, com a língua e a linguagem, em um esquema que, partindo do raciocínio de Rancière, mas não se esgotando nele, estabelece uma outra via de retroalimentação entre a estética e a ética. A poesia de Simões "não é só máquina[s] de resistência e denúncia", mas, uma resistência ao "estereótipo da resistência" (Nascimento 2019: 18). Neste sentido, os mecanismos de inovação/conservação e apropriação/transformação dos cânones poéticos e a busca por novas dicções que se traduzam em diferentes códigos que se procura representar, levam a um sistema que passa por uma fase fortemente experimental e é na sua própria linguagem que elabora novas estruturas epistemológicas, considerando que derrubar estruturas existentes não é suficiente para assegurar a persistência do intercâmbio e da participação que coloca no centro de sua poética uma poesia encarnada, inextrincavelmente transformada em técnicas de escrita e em táticas de combate para dar à poesia, através da linguagem, uma dimensão totalmente performativa.

Esta prática poética é uma forma de perseverança que tem sido marcada por uma abordagem que abrange todo seu trabalho: "Quero que as pessoas prestem atenção nas coisas que faço pelas coisas que eu faço, não porque quem está atrás tem uma evidência pelas questões identitárias e políticas que vêm junto. Quero ser lembrado pelas coisas que faço, que elas tenham valor" (Simões 2018a: para. 21).

Trata-se, portanto, de se instalar na língua do colonizador, dominando todas as suas regras, para produzir uma outra língua; afinal, como observa Simões,

na contracorrente ao combate vai ser cada vez mais importante alguns de nós lembrar, e tenho feito sempre esse papel chato, que a poesia é uma linguagem estética, milenar, que tem cânones que entram em crise graças a esse fluxo de poetas marginais que vão entrando. Mas alguns de nós vão precisar mais dizer que o valor da poesia é também nela mesma: não é arte pela arte nem arte engajada, é tudo junto e misturado, e alguns de nós têm que ter essa responsabilidade com a linguagem. (idem: para. 15; grifo nosso) 
A poesia encarnada, entendida como política da poesia, é solidária com a poesia contemporânea em sua dimensão estÉtica, ou seja, em processos de criação e recepção híbridos entre estética e ética política (um tema inconcluso de nossa cultura democrática que aponta os problemas de uma teoria da justiça, da legitimação do poder e do processo de constituição da pessoa enquanto sujeito social titular de direitos e obrigações). Estes processos servem como antídoto à implantação cistêmica normativa que naturaliza o processo dos regimes de verdade e aos aprisionamentos e modelizações da arte burguesa, propondo, assim, outras "políticas de subjetivação" (Thürler 2019: 13). Quando falamos de estÉtica ${ }^{13}$ pensamos no compromisso ético da arte contemporânea com a sua própria estética, ou seja, ao mesmo tempo em que Simões se expressa através de convenções formais e todo um sistema de critérios que determinam a forma como habilidade de um poeta clássico, o faz sem se subordinar a ele.

Em entrevista a Marcos Dias, Simões revela que o livro Quarenta e Uns Sonetos Catados (2013) é um livro importante em sua carreira, porque durante 21 anos exercitou o poema em forma de soneto: "é um livro de formação, no sentido da formação do escritor mesmo, uma insistência com uma forma clássica tida como uma prova de fogo - hoje mais nem tanto, mas até há algumas décadas um bom poeta tinha que ser um bom sonetista" (Dias 2018: para. 5). Embora Simões se auto defina como uma pessoa não conservadora, entende que as academias têm um aspecto político importante e pertinente:

E sou da universidade, fiz graduação e mestrado em letras. Não uso muito isso na biografia, mas acho que é importante, porque eu também sou resultado de um investimento em políticas públicas ligadas a uma universidade pública, que fez um curso extremamente tradicional. $E$, com todas as minhas questões, eu sou o que sou em parte porque existem universidades com cursos de letras e existem academias de letras que fazem coisas que acho interessantes e outras que não, mas não são referências de que eu possa abrir mão. (Simões 2018a: para. 7)

A dicção poética de Simões, desse modo, se empenha em brincar, mas "mui seriamente" (Simões 2018b: 73) com os padrões vigentes de qualidade literária, de densidade hermenêutica do texto poético, da exigência de um leitor qualificado para a plena fruição do poema e seus intertextos, na leitura de Julia Kristeva (1967), ${ }^{14}$ tal como de seus subtextos, operando, esteticamente, a potência deflagradora de novos espaços criativos e solidários, o espaço do outro, esquecido pela cultura ocidental e descartado devido ao seu caráter marginal e inconstante, se configurando, então, como o espaço das heterotopias (Foucault 2013).

Nas heterotopias, o outro tem voz, língua, a língua que chicoteia o ar, mas sua língua não é apenas instrumento, utensílio ou matéria (Novarina 2009) não se dá mais como um veículo através do qual se constrói uma narrativa de conteúdo fabular; a língua política, neste caso, é o próprio conteúdo, o próprio assunto que se problematiza, porque, 
o mundo é por nós furado, revirado, mudado ao falar. Tudo o que pretende estar aqui como um real aparente pode ser por nós subtraído ao falar. As palavras não vêm mostrar coisas, dar-lhes lugar, agradecer-lhes educadamente por estarem aqui, mas antes parti-las e derrubá-las. "A língua é o chicote do ar", dizia Alcuíno; ela é também o chicote do mundo que ela designa. (Novarina 2003: 15)

A poesia encarnada de Simões enquanto língua política não desconecta com o entorno, é produto da sociedade e, como tal, exprime ou reflete formas de vida e, ao mesmo tempo, através da recepção, tem algum efeito sobre formas de afetar a sociedade. Não é apenas um instrumento, mas também um terreno de negociação, exploração e apropriação a fim de alcançar a autodeterminação do sujeito desde a sua condição de marginalidade.

Essa língua política, pensada assim, é a que fragmenta, que questiona, que derruba; a língua-soco, a língua-pontapé futurista que pode ser percebida na poética do movimento negro que reivindicava nas ruas a busca de seus direitos, de seu reconhecimento e de visibilidade e respeito que historicamente lhes fora usurpado pela instauração de um "projeto de nação" (Miskolci 2013) estruturado através da modernidade/colonialidade, em que alguns privilégios e hierarquias foram historicamente naturalizados (Grosfoquel 2012).

E para finalizar, em relação ao nosso percurso de investigação e aos seus interesses, a poesia encarnada de Alex Simões parece então ser capaz de acompanhar ou mesmo encarnar uma tal relação entre poesia e política, e tende a desenhar uma estÉtica que seria, ao mesmo tempo, autônoma e crítica, intransitiva e utópica, igualitária e emancipatória, poesia enquanto forma que intervém na distribuição geral dos modos de ser e de ver, ou, para dizer de outra forma, a arte para oferecer uma nova partilha de espaços e ideias.

\section{NOTAS}

* Djalma Thürler é membro do GT Arte y Política da CLACSO e especialista em gestão e políticas culturais pela Universidade de Girona (ESP). Investigador Pleno do do CULT - Centro de Pesquisa Multidisciplinar em Cultura, da UFBA e Investigador Colaborador do ILCML - Instituto de Literatura Comparada Margarida Losa, da Universidade do Porto (Portugal). É diretor artístico e dramaturgo da ATeliê voadOR Teatro (http:// www.atelievoadorteatro.com.br/). É Professor permanente do Programa Multidisciplinar de Pós-Graduação em Cultura e Sociedade e Professor Associado II do Instituto de Humanidades, Artes e Ciências (IHAC) da 
Universidade Federal da Bahia (UFBA). É Doutor em Letras com estudos nas áreas de Literatura Brasileira e Teatro (UFF). É Vice-Coordenador do NuCuS - Núcleo de Pesquisa e Extensão em Cultura e Sexualidade (UFBA) e atual Coordenador Adjunto Acadêmico da Câmara II - Sociais e Humanidades, da Área Interdisciplinar da CAPES.

**Duda Woyda é doutorando da Linha de Pesquisa em Artes do Programa Multidisciplinar de Pós-Graduação em Cultura e Sociedade, da Universidade Federal da Bahia (UFBA). É investigador da ATeliê voadOR Teatro (http://www.atelievoadorteatro.com.br/). Pesquisa questões relacionadas ao corpo e às infiltrações da arte contemporânea no teatro, especialmente a relação entre dramaturgia corporal, gênero e teatralidade.

1 "um texto faz parte da história daqueles que o promoveram" (tradução nossa).

2 "O que é então poesia? Quem sabe quem o dirá? O que é a alma? Podemos - todos nós o fizemos na faculdade - analisar um poema, estudar composição, vocabulário, ritmo, rima, harmonia. Tudo isto é poesia, o que é um coração palpitante para a alma. Uma manifestação externa, não uma explicação, muito menos uma definição. Portanto, se eu quisesse me aproximar de uma definição de poesia, preferiria procurá-la em seus efeitos. Quando um poema, ou simplesmente uma linha, causa ao leitor uma espécie de choque, puxa-o para fora de si mesmo, jogando-o em um sonho, ou, ao contrário, força-o a ir mais fundo dentro de si mesmo até ser confrontado com o ser e o destino, o sucesso poético é reconhecido por estes sinais" (tradução nossa).

${ }^{3}$ Manteremos a grafia conforme sua publicação, em letras minúsculas e em três sílabas: trans-formas-são.

${ }^{4}$ Apresentaremos mais adiante o conceito deste neologismo.

${ }^{5}$ Maiores informações sobre o lançamento do livro na Chapada Diamantina (BA) podem ser consultadas em http://www.guiachapadadiamantina.com.br/lancamento-do-livro-trans-formas-sao-de-alex-simoes/.

${ }^{6}$ Blog do poeta: https://toobitornottoobit.blogspot.com/2018/06/45.html. (último acesso em 20/08/2020).

${ }^{7}$ Àgò, segundo o Site Educa Yorubá, é uma palavra em Yorùbá que expressa um pedido de licença, dar passagem, espaço para algo passar ou alguém.

${ }^{8}$ Blog do poeta: https://toobitornottoobit.blogspot.com/2014/03/eu-canto-pras-paredes.html. (último acesso em 10/08/2020).

${ }_{9}$ Blog do poeta: https://toobitornottoobit.blogspot.com

10 "A política é o encontro de dois processos heterogêneos. A primeira é a do governo. Consiste em organizar a reunião de homens na comunidade e o seu consentimento e baseia-se na distribuição hierárquica de lugares e funções. Vou chamar a este processo de polícia. A segunda é a da igualdade. Consiste na interação de práticas guiadas pelo pressuposto da igualdade de qualquer pessoa com qualquer coisa e pela preocupação de a verificar. O nome mais apropriado para este jogo é emancipação" (tradução nossa).

${ }^{11}$ É professor associado da Universidade Federal do Rio de Janeiro (UFRJ) e pesquisador do Conselho Nacional de Desenvolvimento Científico e Tecnológico (CNPq).

12 Para Trói, o termo artivismo recebe a grafia a(r)tivismo: "a suspeição do termo artivismo com a inclusão do (r) tem três objetivos: 1 - criar uma intersecção com o teat(r)o; 2 - marcar o entre lugar entre arte e ativismo; e 3 - evidenciar, a partir da escrita, uma não consensualidade em relação ao conceito, levando em conta os conflitos no campo a partir de binômios como teatro $x$ performance, técnica $x$ enunciação, institucional $x$ anárquico, molar x molecular, esferas contidas nos dois polos de análise propostos nesta dissertação" (Trói 2018: 70 e 71). 
${ }^{13}$ Grafado assim mesmo, com destaque para a segunda letra "E”.

14 "Tout texte se construit comme mosaïque de citations, tout texte est absorption et transformation d'un autre texte. A la place de la notion d'intersubjectivité s'installe celle d'intertextualité, et le langage poétique se lit, au moins, comme double" (Kristeva 1967: 440).

\section{BIBLIOGRAFIA}

Aleixo, Ricardo (2018), "Entrelugares, Entretempos”. [A. do livro] Alex Simões. trans formas são. Salvador: Organismo Editora.

Barbieri, Ivo (1997), Geometria da composição: morte e vida na palavra severina. Rio de Janeiro: Sette Letras.

Boas, Alexandre Gomes Vilas (2015), A(r)tivismo: Arte + Política + Ativismo - Sistemas Híbridos em Ação. São Paulo: Dissertação Mestrado. Programa de Pós-Graduaçao em Artes Visuais. Universidade Estadual Paulista.

Brandão, Fabrício (2016), "Diversos Afins: entre caminhos e palavras". <http://diversosafins.com.br/diversos/pequena-sabatina-ao-artista-44/>. (último acesso em: 20/08/2020)

Carvalho, Sérgio (2020), Facebook. <https://web.facebook.com/sergio.decarvalho.777/ posts/2796737503902831>. (último acesso em: 20/08/2020.)

Colling, Leandro (2017), "Artivismo das dissidências sexuais e de gênero". Revista CULT. 2017, n. 226, Ano 20, 18-34.

-- (2019), Gênero e sexualidade na atualidade. Salvador: UFBA, Instituto de Humanidades, Artes e Ciências; Superintendência de Educação a Distância.

Correio Nagô (2018), "Poeta e performer Alex Simões lança livro 18 deste mês". 7 de agosto de 2018 <https://correionago.com.br/portal/poeta-e-performer-alex-simoes-lanca-livro-18-deste-mes>. (último acesso em 10/08/2020).

Dias, Marcos (2018), "Alex Simões: "Em períodos de crises, a poesia passa a ter alguma relevância social”. 4 de dezembro de 2018. https://atarde.uol.com.br/muito/ noticias/2016351-alex-simoes-em-periodos-de-crises-a-poesia-passa-a-ter-alguma-relevancia-social>. (último acesso em 15/08/2020).

Foucault, Michel (2013), o corpo utópico e as heterotopias. São Paulo: n-1 edições. Genette, Gérard (1972), Poétique et histoire. Figures III. Paris: Seuil. Coll. Poétique. Hollanda, Heloisa Buarque de (2019), Onde é que eu estou?: Heloisa Buarque de Hollanda 8.0. Org. André Botelho et al. Rio de Janeiro: Bazar do Tempo.

Kristeva, Julia (1967), Bakhtine, le mot, le dialogue et le roman. Critique. Paris: Minuit. 
Lucas, Carlos Henrique de/ Carlana Faria Rocha/ Anselmo Peres Alós (2020), "Emergência e urgências dos artivismos de(s)coloniais: o ato 'nosso luto, nossa luta'por Brumadinho (Minas Gerais)", Rev. Eletrônica Mestrado Educação Ambiental. Vol. Dossiê temático: Imagens: resistências e criações cotidianas, 65-85 .

Mbembe, Achille (2018), Necropolítica: biopoder, soberania, estade de exceção, política da morte. São Paulo: $n-1$ edições.

Miskolci, Richard (2012a), O desejo da nação: masculinidade e branquitude no Brasil de fins do XIX. São Paulo: Annablume Editora/FAPESP.

-- (2012b), Teoria queer: um aprendizado pelas diferenças. Belo Horizonte: Autêntica: UFOP - Universidade de Ouro Preto.

Nascimento, Tatiana (2019), Cuírlombismo literário. São Paulo: n-1 edições.

-- (2020), “Que território criam as línguas da poesia lésbica negra?", Suplemento Pernambuco, no 170, abr de 2020, 12-17.

Novarina, Valère (2003), Diante da palavra. Rio de Janeiro: 7 Letras, 2003.

Pompidou, Georges (1961), Anthologie de la poésie française. Paris: Librairie générale française, 1961.

Quijano, Aníbal (2007), "Colonialidad del poder y clasificación social”, in El giro decolonial. Reflexiones para una diversidade epistémica más allá del capitalismo global. Bogotá: Universidad Javeriana-Instituto Pensar, Universidad Central-IESCO, Siglo del Hombre Editores, 93-126.

Rancière, Jacques (1996a), "O dissenso". Adauto Novaes (Org.). A crise da razão. São Paulo: Companhia das Letras, 367-382.

-- (1996b), O Desentendimento: política e filosofia. Trad. Angela Leite Lopes. São Paulo: Ed. 34.

-- (2004), Aux bords de la politique. Paris: Gallimard, 2004.

-- (2009), A partilha do sensível: Estética e política. Trad. Mônica Costa Netto. São Paulo: EXO experimental org.; Editora 34.

-- (2019), O espectador emancipado. Trad. Ivone C. Benedetti. São Paulo : WMF Martins Fontes [2012].

Raposo, Paulo (2015), "Artivismo": articulando dissidências, criando insurgências. Cadernos de Arte e Antropologia. vol. 4, n. 2, 03-12.

Rolnik, Suely (2008), “Geopolítica da cafetinagem”. in Fazendo rizoma. São Paulo: hedra, 25-44.

-- (2018), Esferas da insureição: notas para uma vida nao cafetinada. São Paulo: n-1 edições.

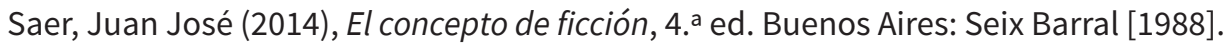

Santos, Valmir (2020), "A arte parelha ao ativismo de grupo". Teatrojornal. <https://teatrojornal.com.br/2020/07/a-arte-parelha-ao-ativismo-de-grupo/\#more-24664>. (último acesso em 14/08/2020).

Segato, Rita (2018), Contra-Pedagogías de la crueldad. Ciudad Autónoma de Buenos Aires: Prometeo Libros. 
Simões, Alex (2018a), "Em períodos de crises, a poesia passa a ter alguma relevância social", A Tarde, 4 de dezembro <https://atarde.uol.com.br/muito/noticias/2016351alex-simoes-em-periodos-de-crises-a-poesia-passa-a-ter-alguma-relevanciasocial> (último acesso em 4/12/2020).

-- (2018b), trans formas são. Salvador: Organismo Editora.

Simas, Luiz Antonio / Luiz Rufino (2019), Flecha no tempo. Rio de Janeiro: Mórula.

Thürler, Djalma (2011), "Shortbus: um diálogo entre o corpo e a cidade - aspectos dsa subcultura (homo)erótica ou um pau duro não acredita em Deus" in Crítica Cultural e Educação Básica: Diagnósticos, proposições e novos agenciamentos. São Paulo: Cultura Acadêmica, 243-252

-- (2019), Sexualidade e políticas de subjetivação no campo das artes. Salvador: UFBA, Instituto de Humanidades, Artes e Ciências; Superintendência de Educação a Distância.

Trói, Marcelo De (2018), Corpo dissidente e desaprendizagem: do Teat(r)o Oficina aos Artivismos queer. Salvador: Dissertação Mestrado. Programa de Pós-Graduação em Cultura e Sociedade, UFBA.

Vergueiro, Viviane (2015), Por inflexões decoloniais de corpos e identidades de gênero inconformes: uma análise autoetnográfica da cisgeneridade como normatividade. Salvador: Dissertação de Mestrado. Programa Multidisciplinar de Pós- Graduação em Cultura e Sociedade, UFBA.

Vilar, Gerard (2017), Precariedad, estética y política. Almería: El Círculo Rojo. 